Research Paper

\title{
Can high school students help to improve breast radiologists in detecting missed breast cancer lesions on full-field digital mammography?
}

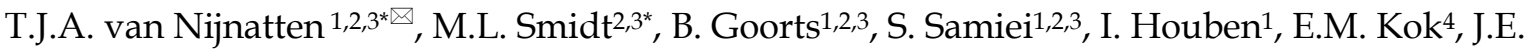 \\ Wildberger ${ }^{1}$, S.G.F. Robben ${ }^{1}$, M.B.I. Lobbes ${ }^{1,3}$ \\ 1. Department of Radiology and Nuclear Medicine, Maastricht University Medical Center+, Maastricht, the Netherlands. \\ 2. Department of Surgery, Maastricht University Medical Center+, Maastricht, the Netherlands. \\ 3. GROW - School for Oncology and Developmental Biology, Maastricht University Medical Center+, Maastricht, the Netherlands. \\ 4. School of Health Professions Education, Department of Education Research and Development, Maastricht University Medical Center+, Maastricht, the \\ Netherlands. \\ *Both authors contributed equally to this work
}

$\square$ Corresponding author: Thiemo van Nijnatten, Department of Radiology and Nuclear Medicine, Maastricht University Medical Center+, P.O. Box 5800, 6202 AZ Maastricht, The Netherlands. Phone: +31 43 388 1575; Fax: +31 43 387 5473; Mail: T.vannijnatten@maastrichtuniversity.nl

(c) Ivyspring International Publisher. This is an open access article distributed under the terms of the Creative Commons Attribution (CC BY-NC) license (https:// creativecommons.org/licenses/by-nc/4.0/). See http://ivyspring.com/terms for full terms and conditions.

Received: 2018.10.08; Accepted: 2018.10.30; Published: 2019.01.01

\begin{abstract}
Aim: To investigate whether full-field digital mammography (FFDM) and contrast-enhanced mammography (CEM), evaluated by non-experienced high school students, improves detection of missed breast cancer lesions on FFDM, in the same cohort of patients.

Methods: Non-experienced first- and second year high school students examined fourteen cases of patients diagnosed with breast cancer. These cases consisted of missed breast cancer lesions on FFDM by a breast radiologist. Sensitivity of assessment of the students on FFDM and CEM was analysed and compared with the initial results of the breast radiologists.

Results: A total of 134 high school students participated in this study. Mean age was 12.8 years (range 10-14). Based on FFDM, mean overall sensitivity of the students was $29.2 \%$ (18.9-39.6\%). When recombined CEM images were used, mean overall sensitivity of students improved to $82.6 \%$ $(74.0-91.2 \%)(p=0.001)$. Mean overall sensitivity of FFDM exams evaluated by radiologists was $75.7 \%$ (64.2 - 87.3\%), which was lower when compared to student's evaluations on recombined CEM exams, yet not statistically significant $(p=0.098)$.

Conclusions: Contrast-enhanced mammography evaluated by non-experienced high school students might improve detection rate of breast cancer when compared to evaluations of only full-field digital mammography by radiologists.
\end{abstract}

Key words: mammography, contrast-enhanced mammography, breast cancer, sensitivity, students

\section{Introduction}

Over the last decades, breast cancer incidence increased from 541,000 in 1975 towards more than 1,6 million in 2012 [1;2]. Breast cancer death rates have been stable or have even slightly decreased since 1990 in Northern America and higher-resource European countries, because of the improved treatment strategies and early detection by (screening) mammography [2; 3]. In breast cancer imaging mammography continues to play a pivotal role in detecting patients in an early phase of disease, in order to obtain the most beneficial and prognostic outcome.

The mean sensitivity of full-field digital mammography (FFDM) is $80 \%$ [4]. Interpretation of 
FFDM can be especially challenging in more dense breast tissue or if lesions are smaller [5-7]. Sensitivity can even drop to $61 \%$ when women have extremely dense breasts [8]. As a result, a sensitivity of $80 \%$ is considered acceptable as reading performance among radiologists, but higher accuracy is strongly preferred to further optimize breast cancer detection [9].

Consequently, new techniques were and are developed in order to improve diagnostic performance of FFDM, like the introduction of contrast-enhanced mammography (CEM) [10]. In CEM, an iodine-based contrast agent is intravenously administered prior to image acquisition. A typical CEM exam consists of a low- and high-energy image of both breasts in two different projection views [11]. The low-energy image is comparable to FFDM, whereas the high-energy images are used to generate a recombined image, in which areas of iodine accumulation can be visualized [12; 13]. A meta-analysis of Tagliafico et al. demonstrated that the sensitivity of CEM is superior compared to FFDM, with a pooled sensitivity of $98 \%$ compared to previously reported sensitivity of $80 \%$ on FFDM [4; 14].

Also, the learning curve of CEM seems to be shorter than FFDM. Prior studies have shown that CEM improves the diagnostic performance of experienced and less experienced readers (i.e. breast radiologists without previous CEM experience and radiology residents) when compared to FFDM [15; 16]. If evaluation of CEM by non-experienced readers (even without any dedicated radiological training) could outperform FFDM assessed by experienced breast radiologists, the importance of CEM as breast imaging tool would be further underlined, especially in potential future settings where automated image-based feature analysis (i.e. radiomics) are involved to improve breast cancer detection rate [17].

Therefore, the current aim of this study was to investigate the diagnostic performance of FFDM and CEM in truly non-experienced readers (i.e. high school students) in a cohort consisting of patients with missed breast cancer lesions according to prior FFDM evaluations by breast radiologists.

\section{Material and methods}

\section{Patient cohort}

The local medical ethical committee of Maastricht UMC+ waived the requirement for obtaining informed consent from included patients and participants. In this study, we used cases from a previously published study by Lalji et al. [16]. In their study, seven dedicated breast radiologists and three radiology residents independently evaluated a cohort of 199 patients, referred from the breast cancer screening programme, who underwent both FFDM and CEM exams.

\section{Case selection and image analysis}

For the present study, a total of fourteen cases with missed breast cancer lesions were collected from the study of Lalji et al. [16]. All these cases consisted of unifocal breast cancer, but were missed on FFDM by at least one of the (expert) readers from the previous study. The ipsilateral images of both FFDM and CEM with best visualisation of the breast cancer lesion (either cranio-caudal view (CC) or mediolateral oblique view (MLO)) were collected and prepared as online test on commercially available online software system Qualtrics ${ }^{\circledR}$ (Qualtrics, Washington, District of Columbia, USA). A single view image of FFDM was followed by the same view (CC or MLO) on the recombined image of the CEM exam. The online test demonstrated the FFDM images first, followed by the recombined CEM images. A region of interest of the primary tumour on each FFDM and CEM image was drawn in consensus by a radiology resident (T.v.N.) and an expert breast radiologist with eight years of dedicated breast imaging expertise (M.L.) (Figure 1).

\section{Participants}

The participants in this study consisted of students that were involved in a six-year pre-university education, which is comparable to obtaining a General Certificate of Education A-level in the United Kingdom [18]. All students were in their first or second year of education.

\section{Reading instructions}

First, a short introduction on breast cancer and CEM was presented. This introduction consisted of a brief overview of pathology, prognosis and treatment options of breast cancer (surgery, systemic therapy and radiotherapy), followed by a description of FFDM and CEM. For the online test, students were instructed to click on the most suspicious breast lesion on FFDM, according to their own interpretation, and subsequently click on the most suspicious (i.e. whitest coloured) breast lesion on the recombined CEM image within the breast.

Students were unaware of any clinical patient information. The online test was constructed to force one click per image before continuing to the next page. Students were unable to review previous pages of the test. Furthermore, students received no feedback on their performance while scoring. All fourteen cases were finished within one session. Total time of the test per student was automatically calculated by the online test. 


\section{Statistics}

Data were analysed using Statistical Package for the Social Sciences software (version 24.0, Armonk, New York, USA). Sensitivity was calculated as the number of correctly identified breast cancer lesions (true positives) per case divided by the total number of students per case (true positives + false negatives). Variance of the sensitivity for all students was adjusted with the variance inflation factor (VIF). Adjusted 95\% confidence intervals (CI) were calculated using an excel spreadsheet provided by Genders et al. [19]. Difference in mean number of true positives between FFDM and recombined CEM exams evaluated by students was calculated by using paired samples T-test. Difference in mean number of true positives between recombined CEM exams evaluated by students and FFDM exams evaluated by radiologists was calculated by using independent samples T-test. Statistical significance was considered P-value $<0.05$.

\section{Results}

\section{General patient characteristics}

Mean age of the fourteen included patients was 58 years (range 49 - 68 years). Most cases concerned invasive carcinoma NST (no special type, 71\%), $\mathrm{ER} / \mathrm{PR}+$ (estrogen/progesterone positive) and HER2- (Human Epidermal growth factor Receptor 2 negative) tumours (79\%) and grade 1-2 tumours (86\%). Mean pathologic tumour size was $13 \mathrm{~mm}$ (range 5 - $40 \mathrm{~mm}$ ) (Table 1).

Table 1. Overview of general patient characteristics

\begin{tabular}{|c|c|}
\hline Mean age (years) (range) & $57.6(49-68)$ \\
\hline \multicolumn{2}{|l|}{ Histopathology (\%) } \\
\hline Invasive carcinoma NST & $10(71.4)$ \\
\hline ILC & $3(21.4)$ \\
\hline DCIS & $1(7.2)$ \\
\hline \multicolumn{2}{|l|}{ Receptor status (\%) } \\
\hline ER/PR+, HER2- & 11 (78.6) \\
\hline Triple negative & $2(14.3)$ \\
\hline Missing & 1 \\
\hline \multicolumn{2}{|l|}{ Tumour grade (\%) } \\
\hline $1-2$ & $12(85.8)$ \\
\hline 3 & $1(7.1)$ \\
\hline Missing & 1 \\
\hline $\begin{array}{l}\text { Mean pathologic tumour size (mm) } \\
\text { (range) }\end{array}$ & $13(5-40)$ \\
\hline
\end{tabular}

\section{General student characteristics}

A total of 134 high school students, with a mean age of 12.8 years (range 10-14 years), participated in this study. Male to female ratio was nearly 2:1 (64.9\% versus $35.1 \%$ ). Most students were in their first year of education $(65.7 \%)$ (Table 2$)$.
Table 2. Overview of high school students $(n=134)$

\begin{tabular}{lcc}
\hline Age (years) (\%) & & \\
& 10 & $(0.7)$ \\
& 11 & $5(3.7)$ \\
& 12 & $44(32.8)$ \\
& 13 & $54(40.3)$ \\
& 14 & $30(22.4)$ \\
Male (\%) & $87(64.9)$ \\
High school class (\%) & \\
\multicolumn{2}{c}{ First year students } & $88(65.7)$ \\
\multicolumn{2}{c}{ Second year students } & $46(34.3)$ \\
\hline
\end{tabular}

\section{Reading performance}

Mean overall reading time of all students was 5.25 minutes (range 2.57 minutes - 14.60 minutes). Based on FFDM, overall mean sensitivity of students was $29.2 \%(18.9-39.6 \%)$. Using the recombined image of the CEM exam, mean sensitivity improved to $82.6 \%$ $(74.0$ - 91.2\%) $(\mathrm{p}<0.001) \quad$ (Table 3). Mean overall sensitivity of the radiologists on FFDM was $75.7 \%$ $(64.2$ - 87.3\%), which was lower compared to student's evaluations on recombined CEM exams, yet not statistically significant $(p=0.098)$.

Table 3. Overview of sensitivity for FFDM and CEM findings of high school students and radiologists

\begin{tabular}{|c|c|c|c|}
\hline $\begin{array}{c}\text { Case } \\
\text { number }\end{array}$ & $\begin{array}{c}\text { Sensitivity FFDM } \\
\text { students (\%) }(95 \% \mathrm{CI}) \\
{[\mathrm{n}]}\end{array}$ & $\begin{array}{c}\text { Sensitivity CEM } \\
\text { students (\%) }(95 \% \mathrm{CI}) \\
{[\mathrm{n}]}\end{array}$ & $\begin{array}{c}\text { Sensitivity FFDM } \\
\text { radiologists (\%) (95\% } \\
\text { CI) [n] }\end{array}$ \\
\hline 1 & $\begin{array}{c}1.5[0.2-5.8] \\
{[2 / 134]}\end{array}$ & $\begin{array}{c}7.5(3.8-13.6) \\
{[10 / 134]}\end{array}$ & $\begin{array}{c}60.0(27.4-86.3) \\
{[6 / 10]}\end{array}$ \\
\hline 2 & $\begin{array}{c}0(0-3.5) \\
{[0 / 134]}\end{array}$ & $\begin{array}{c}95.5(90.1-98.2) \\
{[128 / 134]}\end{array}$ & $\begin{array}{c}80.0(44.2-96.5) \\
{[8 / 10]}\end{array}$ \\
\hline 3 & $\begin{array}{c}3.0(1.0-7.9) \\
{[4 / 134]}\end{array}$ & $\begin{array}{c}94.0(88.2-97.2) \\
{[126 / 134]}\end{array}$ & $\begin{array}{c}80.0(44.2-96.5) \\
{[8 / 10]}\end{array}$ \\
\hline 4 & $\begin{array}{c}88.8(81.9-93.4) \\
{[119 / 134]}\end{array}$ & $\begin{array}{c}36.6(28.5-45.4) \\
{[49 / 134]}\end{array}$ & $\begin{array}{c}80.0(44.2-96.5) \\
{[8 / 10]}\end{array}$ \\
\hline 5 & $\begin{array}{c}3.7(1.4-8.9) \\
{[5 / 134]}\end{array}$ & $\begin{array}{c}84.3(76.8-89.8) \\
{[113 / 134]}\end{array}$ & $\begin{array}{c}40.0(13.7-72.6) \\
{[4 / 10]}\end{array}$ \\
\hline 6 & $\begin{array}{c}97.0(92.1-99.0) \\
{[130 / 134]}\end{array}$ & $\begin{array}{c}100(96.5-100) \\
{[134 / 134]}\end{array}$ & $\begin{array}{c}80.0(44.2-96.5) \\
{[8 / 10]}\end{array}$ \\
\hline 7 & $\begin{array}{c}3.0(1.0-7.9) \\
{[4 / 134]}\end{array}$ & $\begin{array}{c}90.3(83.7-94.5) \\
{[121 / 134]}\end{array}$ & $\begin{array}{c}50.0(20.1-79.9) \\
{[5 / 10]}\end{array}$ \\
\hline 8 & $\begin{array}{c}1.5(0.3-5.8) \\
{[2 / 134]}\end{array}$ & $\begin{array}{c}94.0(88.2-97.2) \\
{[126 / 134]}\end{array}$ & $\begin{array}{c}60.0(27.4-86.3) \\
{[6 / 10]}\end{array}$ \\
\hline 9 & $\begin{array}{c}8.2(4.4-14.6) \\
{[11 / 134]}\end{array}$ & $\begin{array}{c}91.0(84.6-95.1) \\
{[122 / 134]}\end{array}$ & $\begin{array}{c}90.0(54.1-99.5) \\
{[9 / 10]}\end{array}$ \\
\hline 10 & $\begin{array}{c}85.1(77.6-90.4) \\
{[114 / 134]}\end{array}$ & $\begin{array}{c}97.8(93.1-99.4) \\
{[131 / 134]}\end{array}$ & $\begin{array}{c}90.0(54.1-99.5) \\
{[9 / 10]}\end{array}$ \\
\hline 11 & $\begin{array}{c}15.7(10.2-23.2) \\
{[21 / 134]}\end{array}$ & $\begin{array}{c}99.3(95.3-100) \\
{[133 / 134]}\end{array}$ & $\begin{array}{c}90.0(54.1-99.5) \\
{[9 / 10]}\end{array}$ \\
\hline 12 & $\begin{array}{c}3.7(1.4-8.9) \\
{[5 / 134]}\end{array}$ & $\begin{array}{c}98.5(94.2-99.7) \\
{[132 / 134]}\end{array}$ & $\begin{array}{c}90.0(54.1-99.5) \\
{[9 / 10]}\end{array}$ \\
\hline 13 & $\begin{array}{c}3.7(1.4-8.9) \\
{[5 / 134]}\end{array}$ & $\begin{array}{c}70.9(62.3-78.3) \\
{[95 / 134]}\end{array}$ & $\begin{array}{c}90.0(54.1-99.5) \\
{[9 / 10]}\end{array}$ \\
\hline 14 & $\begin{array}{c}94.0(88.2-97.2) \\
{[126 / 134]}\end{array}$ & $\begin{array}{c}97.0(92.1-99.0) \\
{[130 / 134]}\end{array}$ & $\begin{array}{c}80.0(44.2-96.5) \\
{[8 / 10]}\end{array}$ \\
\hline Mean & $29.2(18.9-39.6)$ & $82.6(74.0-91.2)$ & $75.7(64.2-87.3)$ \\
\hline
\end{tabular}

To illustrate, evaluations of students regarding case number 2 are demonstrated in Figure 1. On FFDM, none of the students correctly identified the breast cancer lesion. When the recombined CEM image was shown, $95.5 \%$ of the students correctly identified the breast cancer lesion. 
Figure 2 demonstrates an overview of the student evaluations concerning case number 4 . On FFDM, mean sensitivity of the students was $88.8 \%$ $(81.9$ - 93.4\%). According to the recombined CEM exams sensitivity decreased to $36.6 \%$ (28.5 - 45.4\%), most false-negative results were caused by the calcification in the middle of the breast or the nipple.

a

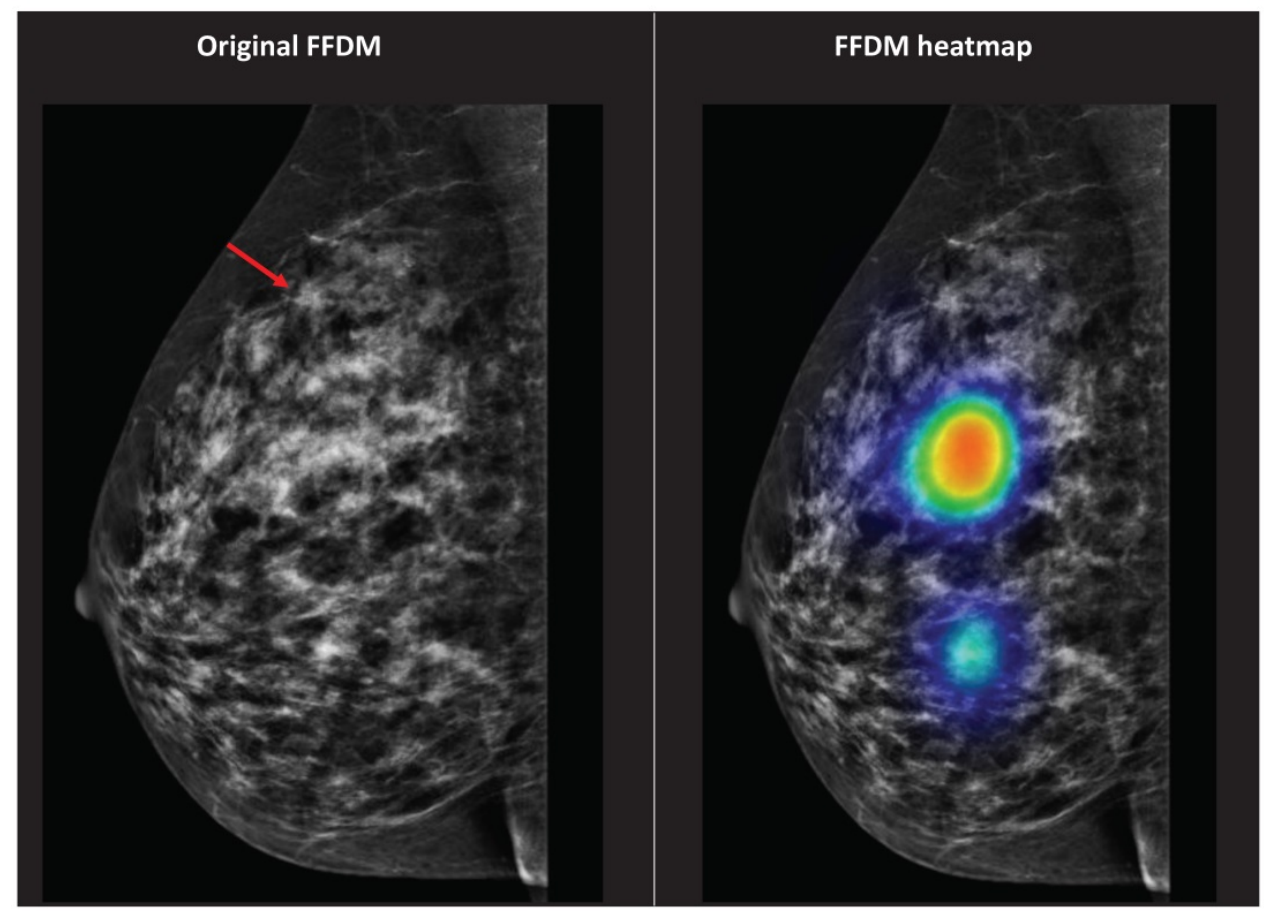

b

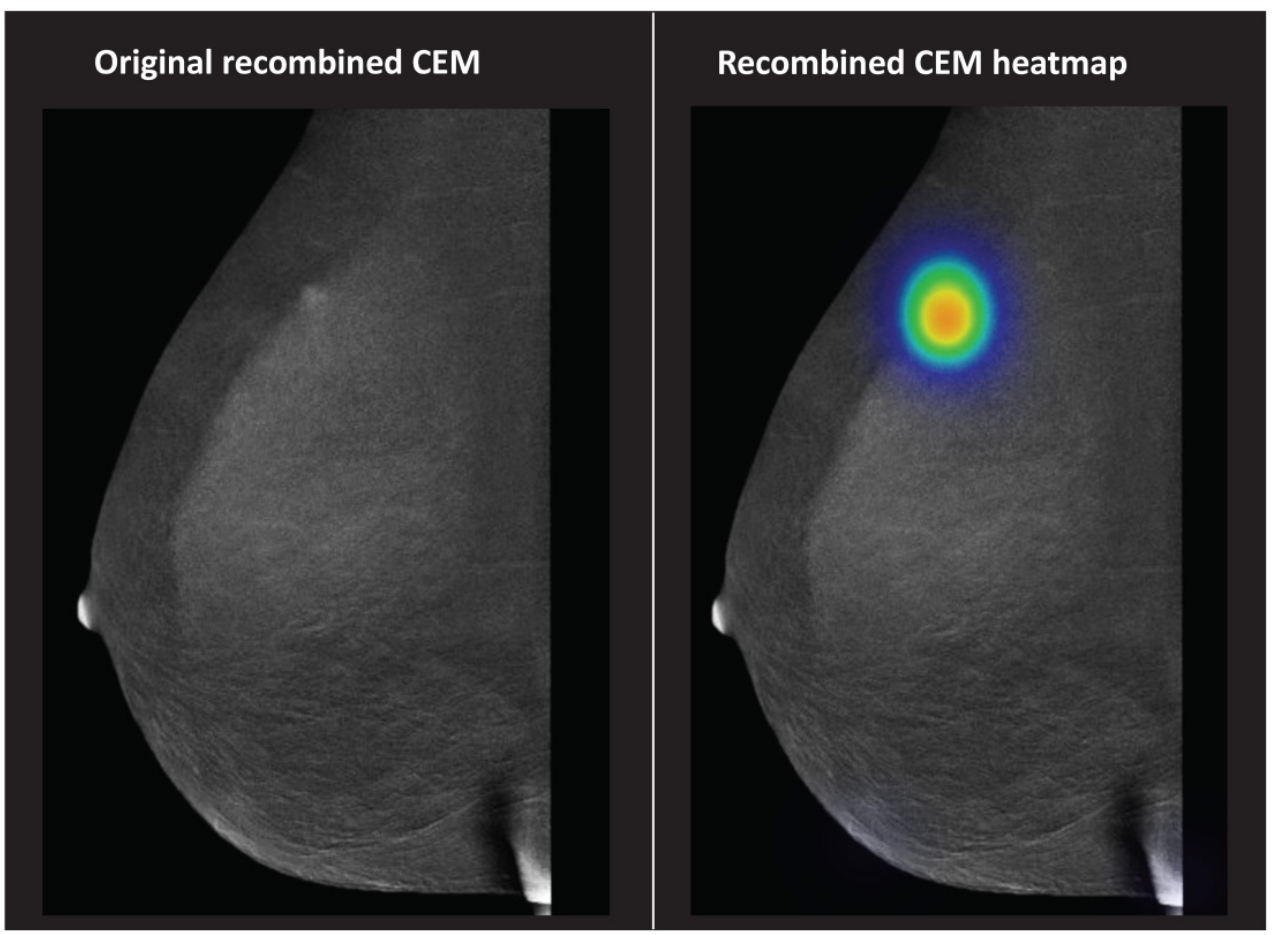

Figure 1. Case number 2 represented a patient with a $13 \mathrm{~mm}$ large invasive lobular carcinoma in her right breast. The red arrow demonstrates the breast cancer lesion, which is presented on the original FFDM and FFDM including heat maps (representation of student evaluations demonstrated in colours) (Figure la). Figure 1b demonstrates the corresponding recombined CEM image. Abbreviations: FFDM full-field digital mammography, CEM contrast-enhanced spectral mammography. 
a

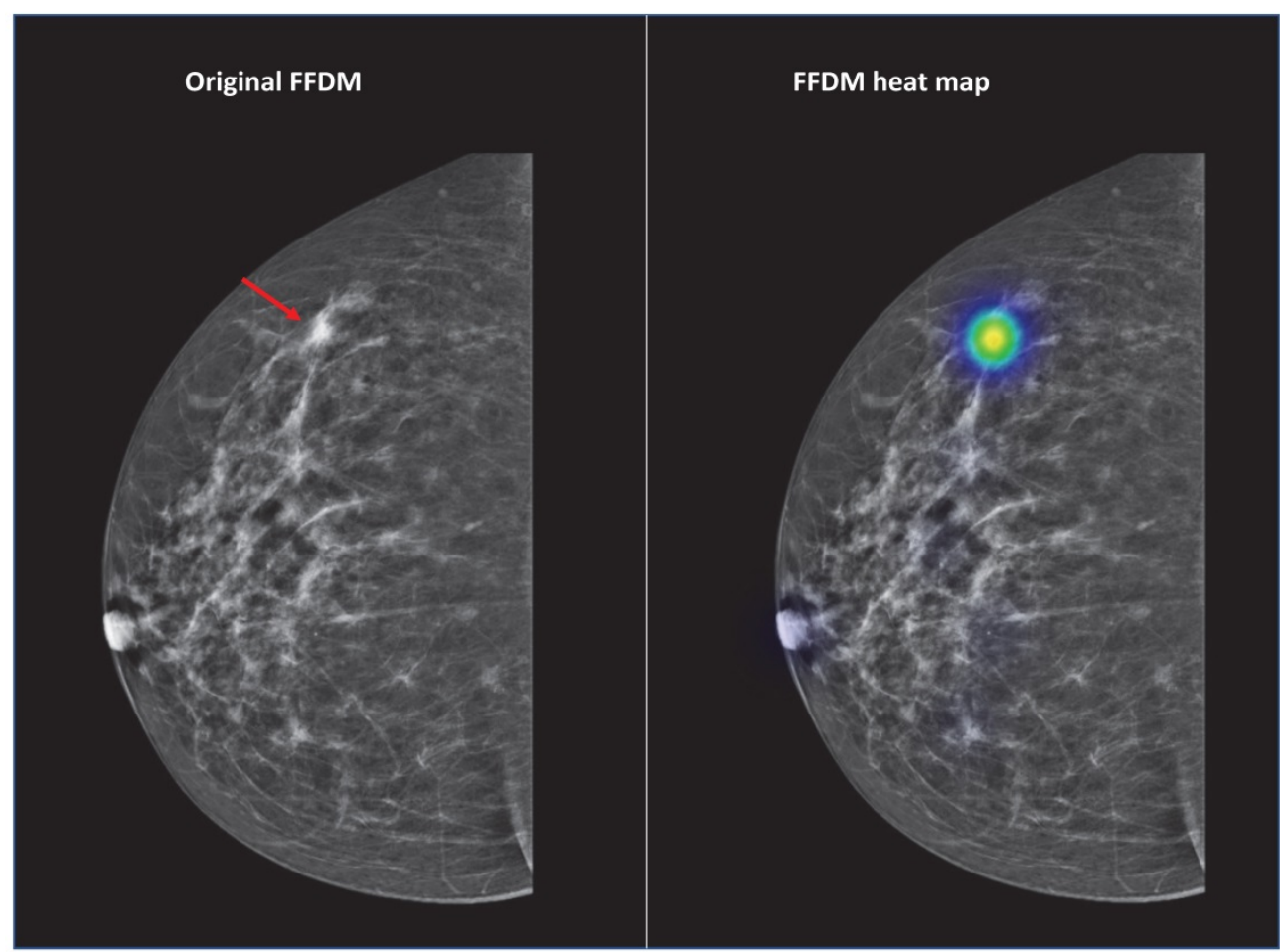

b

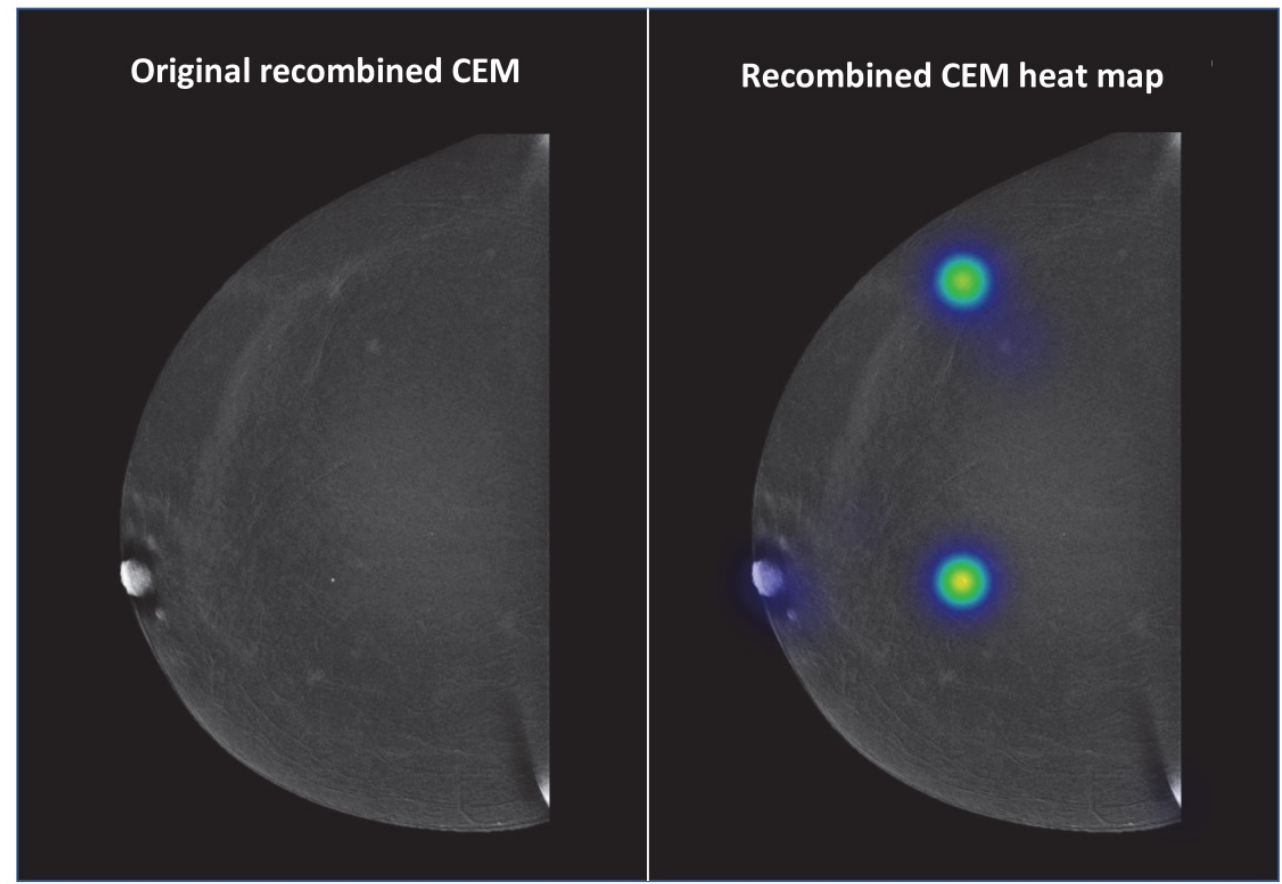

Figure 2. Case number 4 represented a patient with a $5 \mathrm{~mm}$ large invasive lobular carcinoma in her right breast. The red arrow demonstrates the breast cancer lesion on the original FFDM and FFDM including heat maps (representation of student evaluations demonstrated in colours) (Figure 2a). Figure $2 \mathrm{~b}$ demonstrates the corresponding recombined CEM image, including heat maps. Abbreviations: FFDM full-field digital mammography, CEM contrast-enhanced spectral mammography.

\section{Discussion}

This study investigated the diagnostic performance of non-experienced high school students in detecting breast cancer lesions with FFDM and CEM exams, in a cohort consisting of patients with missed breast cancer lesions according to FFDM evaluations previously performed by breast 
radiologists. According to our study, mean overall sensitivity of the students was $29 \%$ on FFDM and increased to $83 \%$ when CEM was used. In addition, sensitivity of CEM seemed slightly higher when compared to FFDM evaluations by breast radiologists, yet not statistically significant $(p=0.098)$. Our results could underline a future potential for automated image-based feature analysis in CEM.

FFDM continues to play an important role in breast cancer imaging, not only for the detection of cancers, but also for evaluation of the extent of disease [20]. However, appropriate interpretation of FFDM requires many years of experience and even after years of experience a large inter-observer variability among radiologists is observed with a sensitivity ranging from 55-82\% [21]. Hence, learning to accurately read FFDM exams is time consuming and requires dedicated training to develop expertise. Previous studies have shown that the learning curve of CEM as opposed to FFDM is almost non-existent, as radiologists both experienced and non-experienced in CEM readings achieved comparable diagnostic performances without any prior dedicated training in CEM reading, with an improved sensitivity of $\geq 90.3 \%$ on CEM compared to $\geq 59.7 \%$ on FFDM [15; 16]. Simplification of reading mammograms, as is the case when CEM is performed, could help to train non-experienced physicians (such as surgeons, medical oncologists and radiotherapists). Our study emphasized the ease with which CEM exams can be interpreted, as even high school students without any knowledge of medical imaging are able to interpret these images.

Enhancement of breast cancer lesions on CEM is achieved by administration of a contrast agent in the circulation. The principle relies on the development of new microvessels, which is required to attain tumour growth. These microvessels are often rapidly formed and consequently may lead to 'leaky' basement membranes. This phenomenon enables a contrast agent, administered in the circulation, to leak through these vessels into the tumour itself, resulting in enhancement [22]. Several imaging techniques, like CEM, use this phenomenon to improve visualisation of the tumour. In CEM, two minutes after administration of an iodine contrast agent a set of low and high-energy images are performed. Acquisition of low energy images are obtained at peak kilovoltage $(\mathrm{kVp})$ values ranging from $26-31 \mathrm{kVp}$, which is below the k-edge of iodine at $33.2 \mathrm{keV}$. High enery images, at $\mathrm{kVp}$ values ranging from 45-49 (i.e. above the k-edge of iodine), are obtained to visualise areas with high concentration of the iodine contrast agent. Yet the high energy images are unable to use for radiologic evaluation. Therefore, recombined CEM exams, consisting of subtraction of low and high-energy mammography images, are performed to visualise areas of contrast enhancement while anatomic noise in the image is neutralized $[11 ; 22]$.

Besides CEM, contrast-enhanced MRI is another imaging technique which uses the same principle of contrast enhancement to visualise breast cancer lesions [13; 23; 24]. Yet, contrast-enhanced MRI is time consuming, more expensive and less favourable according to patient opinion as opposed to CEM [25; 26]. Furthermore, a recent study of Li. et al demonstrated an equal performance of CEM compared to breast MRI for the detection of breast cancer, with a sensitivity of $100 \%$ in both techniques [27]. Therefore, CEM might be able to replace MRI for several indications in near future [28].

The current study had several limitations. First, the cohort of patients consisted of breast cancer patients only. In contrast to the cohort of patients which were previously evaluated by radiologists in the study of Lalji et al., with a prevalence of approximately $30 \%$ of cases with breast cancer [16]. However, the focus of this study was to investigate the ability to detect breast cancer lesions by non-experienced readers, in contrast to investigate a cohort of patients who underwent FFDM and CEM exams.

Second, students assessed FFDM and recombined CEM exams in one direction only (either CC or MLO view), in contrast to clinical daily practice which consists of two views per breast. In addition, students were focussed to detect enhancing lesions rather than detecting breast cancer on CEM, which could potentially be a confounding factor. Yet, the mean sensitivity of $83 \%$ already indicates the important added value of CEM in non-experienced readers, which could potentially even further increase when both views of FFDM and CEM exams were shown or when readers are used to have at least some kind of medical training, albeit not radiological.

Third, the cohort of cases in this study consisted of patients who had unifocal breast cancer. This is an important limitation, since radiologists do not focus only on the detection of breast cancer, but also the extent of breast cancer disease in order to recommend the most optimal surgical treatment plan [29; 30]. Therefore, results of this study should be interpreted with this important limitation in mind. Future research should further explore reading performance regarding assessment of extent of breast cancer disease.

In our study, high school students, without any medical imaging experience, showed a substantial mean sensitivity (i.e. higher than $80 \%$ ) for detecting breast cancer. Consequently, this could create 
possibilities for automated image-based feature analysis like radiomics in future to further improve breast cancer detection rate, for instance in cases of dense breasts on FFDM, which decreases breast cancer detection rate, or BIRADS 0 according to FFDM [17].

In conclusion, contrast-enhanced spectral mammography, evaluated by high school students, might improve the detection of breast cancer when compared to full-field digital mammography evaluations of radiologists. These observations emphasize the ease with which CEM can be interpreted when compared to FFDM, which potentially allows an important role for automated image-based feature analysis.

\section{Acknowledgments}

The authors would like to thank all 134 first- and second year students of the Porta Mosana College (Maastricht, the Netherlands) for their participation in this study. This study did not receive any funding.

\section{Abbreviations}

CEM: Contrast-enhanced mammography; FFDM: full-field digital mammography.

\section{Competing Interests}

The authors have declared that no competing interest exists.

\section{References}

1. Parkin DM, Stjernsward J, Muir CS. Estimates of the worldwide frequency of twelve major cancers. Bull World Health Organ. 1984; 62: 163-82.

2. Torre LA, Bray F, Siegel RL, Ferlay J, Lortet-Tieulent J, Jemal A. Global cancer statistics, 2012. CA Cancer J Clin. 2015; 65: 87-108.

3. Althuis MD, Dozier JM, Anderson WF, Devesa SS, Brinton LA. Global trends in breast cancer incidence and mortality 1973-1997. Int J Epidemiol. 2005; 34: $405-12$

4. Weigel S, Heindel W, Heidrich J, Hense HW, Heidinger O. Digital mammography screening: sensitivity of the programme dependent on breast density. Eur Radiol. 2017; 27: 2744-51.

5. Hoff SR, Samset JH, Abrahamsen AL, Vigeland E, Klepp O, Hofvind S. Missed and true interval and screen-detected breast cancers in a population based screening program. Acad Radiol. 2011; 18: 454-60.

6. Ciatto S, Visioli C, Paci E, Zappa M. Breast density as a determinant of interval cancer at mammographic screening. Br J Cancer. 2004; 90: 393-6.

7. Hoff SR, Abrahamsen AL Samset JH, Vigeland E, Klepp O, Hofvind S. Breast cancer: missed interval and screening-detected cancer at full-field digital mammography and screen-film mammography-- results from a retrospective review. Radiology. 2012; 264: 378-86.

8. Wanders JO, Holland K, Veldhuis WB, Mann RM, Pijnappel RM, Peeters PH, et al. Volumetric breast density affects performance of digital screening mammography. Breast Cancer Res Treat. 2017; 162: 95-103.

9. Carney PA, Parikh J, Sickles EA, Feig SA, Monsees B, Bassett LW, et al. Diagnostic mammography: identifying minimally acceptable interpretive performance criteria. Radiology. 2013; 267: 359-67.

10. Diekmann F, Bick U. Tomosynthesis and contrast-enhanced digital mammography: recent advances in digital mammography. European Radiology. 2007; 17: 3086-92.

11. Dromain C, Balleyguier C, Adler G, Garbay JR, Delaloge S. Contrast-enhanced digital mammography. Eur J Radiol. 2009; 69: 34-42.

12. Lalji UC, Jeukens CR, Houben I, Nelemans PJ, van Engen RE, van Wylick E, et al. Evaluation of low-energy contrast-enhanced spectral mammography images by comparing them to full-field digital mammography using EUREF image quality criteria. Eur Radiol. 2015; 25: 2813-20.

13. Jochelson MS, Dershaw DD, Sung JS, Heerdt AS, Thornton C, Moskowitz CS, et al. Bilateral contrast-enhanced dual-energy digital mammography: feasibility and comparison with conventional digital mammography and MR imaging in women with known breast carcinoma. Radiology. 2013; 266: 743-51.

14. Tagliafico AS, Bignotti B, Rossi F, Signori A, Sormani MP, Vadora F, et al. Diagnostic performance of contrast-enhanced spectral mammography: Systematic review and meta-analysis. Breast. 2016; 28: 13-9.

15. Cheung YC, Lin YC, Wan YL, Yeow KM, Huang PC, Lo YF, et al. Diagnostic performance of dual-energy contrast-enhanced subtracted mammography in dense breasts compared to mammography alone: interobserver blind-reading analysis. Eur Radiol. 2014; 24: 2394-403.

16. Lalji UC, Houben IP, Prevos R, Gommers S, van Goethem M, Vanwetswinkel $\mathrm{S}$, et al. Contrast-enhanced spectral mammography in recalls from the Dutch breast cancer screening program: validation of results in a large multireader, multicase study. Eur Radiol. 2016.

17. Lambin $\mathrm{P}$, Rios-Velazquez $\mathrm{E}$, Leijenaar $\mathrm{R}$, Carvalho $\mathrm{S}$, van Stiphout $\mathrm{RG}$, Granton $P$, et al. Radiomics: extracting more information from medical images using advanced feature analysis. Eur J Cancer. 2012; 48: 441-6.

18. [Internet] Education system United Kingdom. EP-Nuffic. 2nd edition December 2010. Version 3, January 2015. https://www.nuffic.nl/en/publications/ find-a-publication/education-syste m-united-kingdom. Accessed October 2018.

19. Genders TS, Spronk S, Stijnen T, Steyerberg EW, Lesaffre E, Hunink MG. Methods for calculating sensitivity and specificity of clustered data: a tutorial. Radiology. 2012; 265: 910-6.

20. Perry N, Broeders M, de Wolf C, Tornberg S, Holland R, von Karsa L. European guidelines for quality assurance in breast cancer screening and diagnosis. Fourth edition--summary document. Ann Oncol. 2008; 19: 614-22.

21. Klompenhouwer EG, Duijm LE, Voogd AC, den Heeten GJ, Nederend J, Jansen $\mathrm{FH}$, et al. Variations in screening outcome among pairs of screening radiologists at non-blinded double reading of screening mammograms: a population-based study. Eur Radiol. 2014; 24: 1097-104

22. Lobbes MB, Smidt ML, Houwers J, Tjan-Heijnen VC, Wildberger JE. Contrast enhanced mammography: techniques, current results, and potential indications. Clin Radiol. 2013; 68: 935-44.

23. Fallenberg EM, Dromain C, Diekmann F, Engelken F, Krohn M, Singh JM, et al. Contrast-enhanced spectral mammography versus MRI: Initial results in the detection of breast cancer and assessment of tumour size. Eur Radiol. 2014; 24: $256-64$.

24. Lobbes MB, Lalji UC, Nelemans PJ, Houben I, Smidt ML, Heuts E, et al. The quality of tumor size assessment by contrast-enhanced spectral mammography and the benefit of additional breast MRI. J Cancer. 2015; 6: 144-50.

25. Patel BK, Gray RJ, Pockaj BA. Potential Cost Savings of Contrast-Enhanced Digital Mammography. AJR Am J Roentgenol. 2017: 1-7.

26. Hobbs MM, Taylor DB, Buzynski S, Peake RE. Contrast-enhanced spectral mammography (CESM) and contrast enhanced MRI (CEMRI): Patient preferences and tolerance. J Med Imaging Radiat Oncol. 2015; 59: 300-5.

27. Li L, Roth R, Germaine P, Ren S, Lee M, Hunter K, et al. Contrast-enhanced spectral mammography (CESM) versus breast magnetic resonance imaging (MRI): A retrospective comparison in 66 breast lesions. Diagn Interv Imaging. 2017; 98: 113-23.

28. Lobbes MB, Lalji U, Houwers J, Nijssen EC, Nelemans PJ, van Roozendaal L, et al. Contrast-enhanced spectral mammography in patients referred from the breast cancer screening programme. Eur Radiol. 2014; 24: 1668-76.

29. Berg WA, Gutierrez L, NessAiver MS, Carter WB, Bhargavan M, Lewis RS, et al. Diagnostic accuracy of mammography, clinical examination, US, and MR imaging in preoperative assessment of breast cancer. Radiology. 2004; 233: 830-49.

30. Pediconi F, Catalano C, Padula S, Roselli A, Moriconi E, Dominelli V, et al. Contrast-enhanced magnetic resonance mammography: does it affect surgical decision-making in patients with breast cancer? Breast Cancer Res Treat. 2007; 106: $65-74$ 